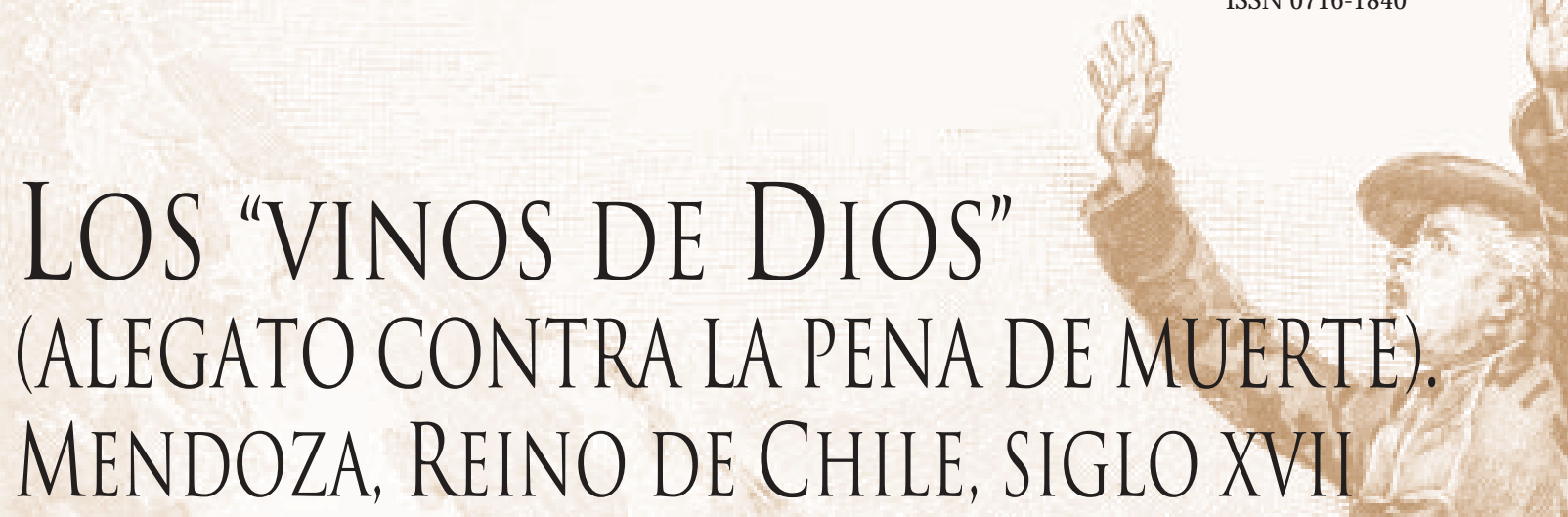

\title{
PABLO LACOSTE*
}

\section{RESUMEN}

El capitán Juan de Puebla y Reinoso era vecino encomendero y miembro del cabildo de Mendoza, capital de la provincia de Cuyo del Reino de Chile. Involucrado en una relación erótica escandalosa, Puebla fue acusado de delito de estupro y condenado a muerte en la horca. La presunta intervención divina le concedió el perdón. Comenzó entonces una nueva vida signada por el éxito social, político y económico. Como resultado, don Juan puso en marcha una familia de empresarios que, con el tiempo, lograría un claro liderazgo en la industria de la vid y el vino en la región que actualmente ocupa el quinto lugar del mundo y el primero de América Latina en viticultura. Se trata de una historia de pasión y escándalo, juntamente con los problemas del rígido sistema legal español y la puesta en marcha de una industria en la frontera sur de América Latina.

Palabras claves: Vitivinicultura, pena de muerte, estupro.

\section{ABSTRACT}

Captain Juan de Puebla y Reinoso was a neighbouring land owner and member of the town council of Mendoza, capital of the province of Cuyo of the Kingdom de Chile. After being involved in a scandalous erotic relationship, Puebla was accused of the crime of rape and condemned to hanging. Presumed divine intervention lead to his pardon after which a new life began for him, marked by social, political and economic success. As a result, don Juan initiated a family of entrepreneurs that over time would achieve clear leadership in the grape and wine industry of the region that currently occupies

*Artículo elaborado en el marco del Proyecto FONDECYT 1051109. El autor desea agradecer los aportes de Luis César Caballero, investigador genealógico.

** Profesor del Instituto de Estudios Humanísticos "Juan Ignacio Molina”, Universidad de Talca. Talca, Chile. E-mail: placoste@utalca.cl

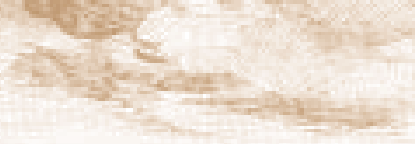


fifth place in world production and first place in Latin American production. Don Juan's story is one of passion and scandal, together with the problems of a rigid Spanish legal system and the initiation of an industry on the southern frontier of Latin America.

Keywords: Vinyards, death penalty, rape.

Recibido: 11.04.2006. Aceptado: 27.10.2006.

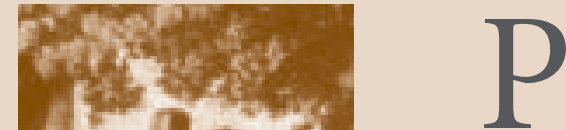

ARA HACER el amor, Juana Bustos y Juan de Puebla y Reinoso eligieron el lugar equivocado y el momento equivocado. Una hacienda de la frontera sur del imperio español, propiedad de la madre de ella, no era el sitio más propicio para un encuentro de este tipo. Sobre todo si corría el año 1632, y el acto de "yacer" con una mujer sin estar casado con ella se consideraba un delito grave, que podía merecer la pena de muerte. Así lo entendió la Real Audiencia de Chile y condenó a don Juan a la horca. El joven cuyano, miembro de una familia destacada por los servicios prestados al Rey, tuvo que verse cara a cara con la muerte cuando apenas tenía 20 años de edad.

Muy pequeña era todavía la ciudad de Mendoza cuando dos miembros de sus familias dirigentes se entregaron a un amor apasionado. Tal vez, Juan y Juana pensaron que podían tener las mismas libertades que otros grupos sociales; no advirtieron que estos caminos eran peligrosos para un miembro del cabildo y la hermana de otro capitular. Sobre todo si el amor se consumaba en forma clandestina, en la casa de una viuda celosa y ambiciosa, capaz de recurrir a la Real Audiencia de Chile para castigar al infractor y despojarlo de sus bienes y su vida.

El amor clandestino de Juan y Juana, por su visibilidad, se enmarcaba en el caso de un "escándalo". Este concepto era muy fuerte para una sociedad tan empapada de la cultura cristiana como las colonias españolas de América. Los curas, vicarios y obispos repetían una y otra vez desde el púlpito las palabras de Jesús en el evangelio de San Mateo: "quien escandaliza a uno de estos niños que creen en mí, más le valdría que lo cuelguen con una piedra enorme y lo arrojen al fondo del mar" ${ }^{\text {. }}$ Los clérigos han sentido la obligación moral de ajustarse a estas palabras, sobre todo en el plano de las costumbres sexuales. Esta situación se ha mantenido vigente hasta el siglo XXI, tal como se reflejó en el conflicto suscitado entre el Vaticano y el gobierno de la República Argentina² . Con mayor razón, el escándalo era considerado

${ }^{1}$ Evangelio según San Mateo, capítulo 18 versículos 6-7.

${ }^{2}$ El 17 de febrero de 2005 el obispo castrense de la República Argentina, monseñor Antonio Baseotto, citó estos versículos del Evangelio como aplicables al ministro de Salud y Ambiente, Ginés González García, por sus enfoques a favor del uso de anticonceptivos y la despenalización del aborto. El Presidente de la Nación, Néstor Kirchner, interpretó las palabras del prelado como 
grave en el siglo XVII, cuando los eclesiásticos tenían poder e influencia. Al no existir una separación entre la Iglesia y el Estado español, el brazo secular se encargaba de castigar severamente a los responsables de los escándalos.

El encuentro amoroso entre Juan y Juana tuvo connotaciones sumamente atrayentes. A la elevada posición de sus protagonistas se añadieron las persecuciones a través de la cordillera de los Andes, la más alta del mundo fuera de Asia. Luego sobrevino un intenso pleito judicial, ventilado en los estrados de la Real Audiencia de Chile, que culminó cuando el pregón anunció públicamente que el reo estaba condenado a la horca. Las autoridades civiles y eclesiásticas pudieron darse por satisfechas al haber cumplido correctamente su tarea de reprimir el escándalo. Pero las circunstancias darían un giro inesperado, aparentemente por intervención divina. Una nueva estrella comenzaría a brillar para don Juan de Puebla y lo conducía de la mano hacia el poder político y el éxito económico. Su historia no tardaría en elevarse a la altura del mito y la leyenda.

\section{EL ESCENARIO Y LOS ACTORES}

El escenario de esta historia fue la ciudad de Mendoza. A pesar de ser fundada muy tempranamente (1561), muy poco logró prosperar en sus primeros cien años. A comienzos del siglo XVII, Mendoza era poco más que una posta en el camino de Buenos Aires a Santiago de Chile. Su significado para el imperio español era el de un pequeño refugio para las tropas que la Corona enviaba a la guerra de Arauco. Los tercios españoles desembarcaban en el Río de la Plata, atravesaban las pampas en carretas y llegaban a Mendoza; allí debían esperar hasta que el camino estuviese transitable antes de reemprender la marcha a través de la Cordillera de los Andes. Mendoza era, por lo tanto, una posta obligada en este camino. En 1601 llegó un primer ejército con 500 hombres en 48 carretas y en 1605 llegó otro mayor, esta vez con 1.000 tropas en 113 carretas, que permanecieron en Mendoza durante cinco meses. En ambas oportunidades, la villa andina debió abastecer de "vino, pan y carne" a los soldados durante todo el invierno y a la vez, proveer de los recursos necesarios para atravesar la cordillera. Ello incluía también "todas las municiones, a saber: arcabuces, mosquetes, picas, palas, azadones y cin-

una reivindicación de la metodología utilizada por los militares argentinos durante la dictadura de 1976-1983, cuando literalmente se usó este método para hacer desaparecer a los ciudadanos en ríos y mares mediante los "Vuelos de la Muerte". Kirchner solicitó al Vaticano la remoción del obispo castrense. Pero el Vaticano volvió a reivindicar literalmente la cita bíblica y respaldó las palabras de Baseotto como ajustadas a la doctrina eclesiástica. Como resultado, el presidente Kirchner destituyó de su cargo a Baseotto (18 de marzo de 2005) y se rehusó a asistir a los funerales del Papa Juan Pablo II (8 de abril de 2005).

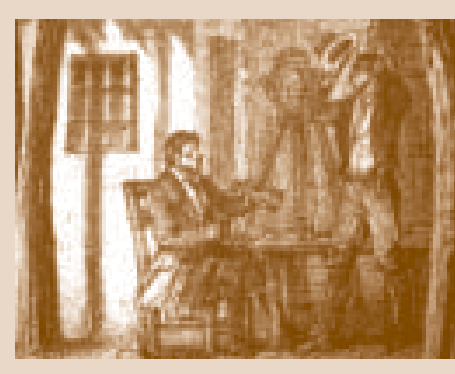


co piezas de artillería, pólvora y cuerda, plomo, hierro y acero" (Draghi, 1993: 22-23).

Hacia 1610, Mendoza contaba apenas con 32 casas, de las cuales sólo una o dos tenían tejas; las demás tenían techos de paja. Lo más relevante era la presencia religiosa, que contaba con tres conventos, pertenecientes a los dominicos, mercedarios y jesuitas, cada uno de ellos con dos religiosos ${ }^{3}$. Mendoza era un espacio de frontera abierta con los pueblos indígenas. Ningún fuerte ni fortín defendía a la ciudad de los eventuales malones indígenas (el primero se instaló en San Carlos en 1770). Por lo tanto, los vecinos tenían que prestar servicios permanentemente en las milicias. Pero el lugar políticamente más importante era el cabildo; aunque Mendoza era muy pequeña, al ostentar el título de ciudad contaba con la sala capitular, lugar donde las élites se reconocían y ejercían el poder local. Sus decisiones eran prácticamente inapelables dado que la cordillera generaba una situación de aislamiento y autonomía de hecho con relación a la autoridad del Gobernador y Capitán General de Chile. Por lo tanto, las funciones militares y políticas eran muy importantes en esta ciudad, casi tanto como las religiosas. Las familias de la élite ocupaban los cargos del cabildo y los mayores grados militares, a la vez que aspiraban a contar con un pariente en los conventos.

La familia de doña Juana Bustos ocupaba un lugar central en la política regional. Su padre era un importante militar, el capitán Agustín de Bustos, vecino encomendero de Mendoza; su madre, una mujer enérgica y decidida, doña Teodora Castañeda. De esta unión nació don Pedro Bustos, también destacado por sus lazos sociales, militares y políticos. Se casó con doña Francisca Godoy, perteneciente a una familia troncal de Cuyo; en terreno de la milicia llegó al grado de sargento mayor; fue miembro del cabildo de Mendoza y, posteriormente, teniente de corregidor y justicia mayor en San Juan (Morales, 1936: 52).

Don Juan de Puebla y Reinoso pertenecía a una de las más encumbradas familias de la elite hispano criolla de la provincia de Cuyo. Era hijo del capitán Gregorio de Puebla y de doña Beatriz de Reinoso y Niño de Zepeda. Su familia gozaba de una posición destacada en la élite local y accedía a los principales espacios sociales y culturales del Reino. Don Gregorio Puebla era un oficial español que llegó a Mendoza como capitán del ejército que el Rey envió a Chile en 1601. Don Gregorio combatió en la Araucanía en la campaña de 1602; a fines de ese año regresó a Santiago de Chile a curar sus heridas y luego traspasó la cordillera para avecindarse en Mendoza. Abandonó la vida militar para dedicarse a la política y a cuidar de sus intereses privados. En Mendoza ocupó altos cargos públicos: fue alcalde ordinario de

\footnotetext{
${ }^{3}$ Informe del doctor Gabriel Celada, oidor de la Real Audiencia de Chile, Mendoza, 10 de enero de 1610. En: Verdaguer, 1932: I, 85.
} 
primer voto (1603), fiel ejecutor, nuevamente alcalde (1610), teniente de corregidor (1623) y regidor (1628) (Peña y Lillo, 1997: 38). Entre sus tareas más difíciles estuvo gestionar el abastecimiento del ejército real que llegó a Mendoza en 1605. Inquieto, agudo observador y crítico de su época, don Gregorio redactó un Memorial al Rey, en el cual daba cuenta de la situación de Mendoza en 1608 y recomendaba medidas para evitar que el cruce de las tropas del Rey no agotara los recursos económicos de Mendoza 4 .

En premio por sus servicios en Arauco, en 1606 el Capitán General de Chile le otorgó una merced real "en que se le concedían 500 cuadras de tierra en el Valle de Uco" (Morales, 1938: 275-278). Don Gregorio logró configurar una posición destacada tanto en el plano económico como político, militar y social. Su matrimonio con doña Beatriz de Reinoso (1603) engendró siete hijos, tres mujeres y cuatro varones. Don Gregorio Puebla falleció en 1630, dejando una familia destacada de la ciudad. Su esposa lo sobrevivió durante más de dos décadas (falleció en 1651), en las cuales tendría la oportunidad de ver la trayectoria de sus hijos.

Los hijos de Gregorio y Beatriz realizaron carreras expectantes. Por ejemplo, una de las mujeres, Beatriz de Puebla y Reinoso o Beatriz de Valverde, recibió una generosa dote que incluía "una chacra en la ciudad de Mendoza, media legua al oriente, tasada en $\$ 250$ y parece tener de cabezadas 50 varas". Con estos bienes Beatriz entró al matrimonio con Jacinto de Urquizo, con el cual puso en marcha un tronco familiar llamado a prosperar con el tiempo. Una hija de esta pareja fue María Tobar Urquizo, la cual recibió en dote, además de la mencionada chacra, una propiedad que incluía esclavos, viñas y 1.000 arrobas de vino por un valor de \$1.500; en total, la dote de Beatriz ascendía a $\$ 6.904$ con 5 reales $^{5}$. Los restantes hijos de Gregorio y Beatriz también gozaron del respaldo económico necesario para alcanzar lugares elevados en la sociedad de la época. El reverendo padre fray Gregorio Puebla y Reinoso estudió en el convento de Santo Domingo en Santiago de Chile (1625) (Lira, 1979: 256). Posteriormente regresó a Mendoza donde ejerció su ministerio y fue el vicario provincial del convento dominico (16341635) (Verdaguer, 1932: I, 245). Más tarde, el padre Gregorio figuraba como prior del Convento de San Francisco (1648) ${ }^{6}$.

Además del brillo e influencia de sus padres y hermanos, don Juan de Puebla y Reinoso estaba emparentado con las figuras más prominentes de la

\footnotetext{
${ }^{4}$ Carta de Gregorio de Puebla a su majestad en que incluye un memorial que trata del estado en que se encuentran las cosas de la provincia de Cuyo a fin de que sirva poner remedio en muchas que son en de servicio de Dios y del Rey, Mendoza, 20 de marzo de 1607, Revista de la Junta de Estudios Históricos de M endoza, tomo IV, $\mathrm{N}^{\circ} 11$ y 12 (Mendoza), diciembre de 1936, pp. 131-133.

${ }^{5}$ Carta de dote de doña María de Tobar Urquizo, Mendoza, 7 de diciembre de 1741. Reproducida en: Draghi (1940: 247-249).

${ }^{6}$ Carta de imposición de capellanía, Mendoza, 9 de julio de 1648. AHM, Protocolo de Escribanos $\mathrm{N}^{\circ} 14$, fols. 72 .
} 
sociedad cuyana. En efecto, el teniente de la ciudad de Mendoza Julio Martínez de Ortubia estaba casado con Ana de Morales, prima hermana de doña Beatriz de Reinoso, madre de don Juan. Además, "el alguacil mayor de la ciudad, Pedro Gómez, estaba casado con Mariana de Puebla, hermana legítima" de Juan. Por otra parte, "el alcalde ordinario de vecinos, capitán Valentín de Córdoba, es íntimo amigo de dicho (Juan de Puebla)" . El prestigio de su abolengo le facilitó el camino a la política. Fue miembro del cabildo, donde prestó servicios de regidor de moradores, fiel ejecutor y alcalde de santa hermandad ${ }^{8}$.

En el Cabildo de Mendoza, don Juan trabó amistad con otro distinguido vecino de la ciudad, don Pedro Bustos, el hermano de Juana. Don Pedro se desempeñó como fiel ejecutor y regidor de vecinos. Además, recibió la vara de la real justicia. En 1630 don Pedro y don Juan se desempeñaron juntos en el Cabildo de Mendoza9 ${ }^{9}$. Es probable que en este ámbito se haya profundizado la relación entre ellos y sus respectivos amigos y parientes, incluyendo en este juego a la hermana de Pedro. Ella vivía con su madre, la ya viuda, doña Teodora de Castañeda. En esta casa se iba a producir el encuentro amoroso que, posteriormente, terminaría en pena de muerte.

\section{LA PENA DE MUERTE EN LA SOCIEDAD COLONIAL}

La pena de muerte era, para la legislación española, un castigo extremo, orientado a reprimir delitos particularmente graves como homicidio, traición, falsificación de moneda, hurto por ladrón consuetudinario o en lugar sagrado, violación o rapto de mujer honesta, bestialidad (zoofilia) y herejía. Según el penalista español José Luis de Las Heras Santos, en tiempo de la Casa de Austria, en España "la pena de muerte se imponía para castigar delitos de lesa majestad o contrarios a la fe, homicidios, homosexualidad, bestialidad y delitos contra la propiedad (...) La mayor parte de los ejecutados por la justicia estaban implicados en homicidios y atentados contra el patrimonio. Mas también otras infracciones, no castigadas habitualmente con tanto rigor, podían ser objeto de la sanción suprema si el juez de la causa convenía empeñarlas más gravemente" (de Las Heras, 1991: 317). Estos rigurosos criterios regían en España en los siglos XVI y XVII, y fueron

\footnotetext{
${ }^{7}$ Juicio contra Juan de Puebla Reinoso por estupro, Santiago de Chile, 14 de abril de 1633. Archivo Nacional de Chile (en adelante AN), Real Audiencia, volumen 3029, fols. 208.

${ }^{8}$ Documento de asuntos varios, Mendoza, 5 de octubre de 1631. AHM, Protocolo de Escribanos $\mathrm{N}^{\circ} 11$, fols. $5 \mathrm{v}$.

${ }^{9}$ La presencia de don Juan de Puebla y don Pedro Bustos en el Cabildo de Mendoza puede verse en Actas Capitulares de Mendoza, 1628-1644.
} 
los que se intentaron trasladar a América. De todos modos, en las Indias se utilizaron criterios más amplios. En el Cono Sur, la pena de muerte se utilizó casi exclusivamente para condenar delitos de homicidio. Así se desprende de los estudios de Abelardo Levaggi para el espacio pampeano-rioplatense, y de los trabajos de Arancibia, Cornejo y González referidos al Reino de Chile (Levaggi, 1975: 89-90, Arancibia et al., 2003). Las penas que más se usaban para reprimir delitos sexuales eran años de presidio. Un panorama de esta situación puede advertirse, por ejemplo, en el presidio de Valdivia, plaza fuerte a la cual se remitían reos del Reino de Chile, el Virreinato del Perú y la Audiencia de Quito. En agosto de 1788 había allí 174 presos, de los cuales siete $(4 \%)$ habían cometido delitos contra mujeres o sexuales. Los crímenes fueron tipificados como estupro (2), agredir a una mujer (1), matar a una mujer (1), excesos (1), por vicioso (1), o por "crimen bestial" (zoofilia) (1) (Molina, 2004). Los actores condenados por delitos de tipo sexual o agresión a mujeres se distinguían por su diferente extracción étnica y territorial. Los autores de delito de estupro fueron el negro José Hurtado (Lima) castigado a ocho años; y el zambo Jerónimo Parra (Chile), con pena de cinco años. El español Juan Atienza (Lima) fue condenado a diez años "por excesos"; el chino Toribio Zúñiga (Lima) fue condenado a diez años por matar a una mujer; el mestizo Santiago Chacón (Lima) recibió condena de siete años por dar heridas a una mujer; el mestizo Mariano Félix (Lima) fue condenado a diez años por "crimen bestial". Como se puede ver, la violencia contra la mujer estaba presente tanto en Chile como en Perú, y se extendía a las distintas castas: españoles peninsulares, mestizos, zambos, negros y "chinos" (Molina, 2004).

El estupro fue una figura legal que animó juicios en todo el imperio español. Y, por lo general, se castigaba al culpable con el pago de una dote a la mujer "ultrajada". En algunos casos se le ordenaba casarse con ella y, en caso de desacato, el hombre era excomulgado, encarcelado y confiscados sus bienes. Así se desprende de los casos examinados por Langue en la Capitanía General de Venezuela. En el Reino de Chile, en cambio, se utilizó otro criterio. En algunos casos se condenó al reo a largos años de prisión.

\section{DEL TALAMO A LA HORCA}

El encuentro amoroso entre don Juan de Puebla y doña Juana Bustos se consumó una noche de 1633 en la casa materna de la mujer. Al parecer, los amantes fueron sorprendidos por doña Teodora, la cual manifestó su severa reprobación. El hombre huyó y la mujer fue interpelada por su madre. Aterrorizada, doña Juana le dijo que había dado su consentimiento "bajo pala- 
bra de casamiento". Esta era una práctica relativamente difundida en la época. La promesa de matrimonio era "un recurso de los hombres para vencer la resistencia de las mujeres a tener relaciones carnales" (García, 1999: 134). $\mathrm{O}$ bien una excusa de las mujeres para liberarse de las amenazas paternas. No se sabe si don Juan de Puebla había asumido ese compromiso con doña Juana; tampoco se ha comprobado si la madre creyó o no en la palabra de su hija. Pero lo cierto es que puso en marcha mecanismos tendientes a capturar y castigar a Juan de Puebla.

La noche del incidente sucedieron varios hechos llamativos. Juan de Puebla logró reunir caballos y amigos para cruzar la Cordillera de los Andes y dirigirse a Chile. Tras una marcha forzada, llegó a la estancia de Chacabuco, donde se detuvo a descansar. Había ganado bastante tiempo porque en Mendoza, el hermano de la doncella, Pedro Bustos, vio frustrado su intento de perseguir a Puebla, pues fue detenido por una extraña orden de las autoridades. De todos modos, la situación cambió y pronto se pusieron en camino los agentes del orden para detener a Puebla. Cuando éste tuvo noticias de la inminente llegada de sus perseguidores, siguió camino hacia Santiago y allí se refugió en el Convento de Santo Domingo ${ }^{10}$.

La huida de don Juan fue posible debido a su red de contactos con los sectores más influyentes de la élite cuyana. Esta red hizo posible que don Juan pudiera, sin tiempo de realizar los preparativos más elementales, cruzar la Cordillera de los Andes y encontrar refugio en la capital del Reino de Chile. Así por ejemplo el alcalde ordinario de vecinos, capitán Valentín de Córdoba, ordenó la detención de Pedro Bustos para facilitarle la fuga a Juan de Puebla y lograr "que no solicitasemos ni hiciéramos diligencia necesaria para su prisión la noche que cometió el crimen", denunció la madre de la víctima ${ }^{11}$. Por otra parte, el alguacil mayor de la ciudad, Pedro Gómez, "lo tuvo oculto después del delito y lo acompañó a esta ciudad (de Santiago) desde la ciudad de Mendoza”. Ello quedó probado por las declaraciones del capitán Gonzalo Martínez de Vergara, el cual, cuando estuvo en la estancia de Chacabuco, "declaró que Juan de Puebla iba acompañado por el alguacil Pedro Gómez"12.

Las acciones judiciales fueron lideradas por la familia de la "víctima", fundamentalmente la madre y el hermano. Por tal motivo iniciaron "querella criminal contra Juan de Puebla Reinoso", el cual, "con poco temor de

\footnotetext{
${ }^{10}$ Juicio contra Juan de Puebla Reinoso por estupro, Santiago, 14 de abril de 1633 . AN, Real Audiencia, volumen 3.029, fols. 207-207 v.

${ }^{11}$ Juicio contra Juan de Puebla Reinoso por estupro, Santiago, 14 de abril de 1633 . AN, Real Audiencia, volumen 3.029, fols. 207-207 v.

${ }^{12}$ Juicio contra Juan de Puebla Reinoso por estupro, Santiago, 14 de abril de 1633 . AN, Real Audiencia, volumen 3.029, fols. 208.
} 
Dios y en menosprecio y deshonor suyo había quebrantado las paredes de su morada, entrando por las paredes a deshoras de la noche, había estuprado debajo de palabra de casamiento a doña Juana Bustos, su hija legítima, doncella a quien tenía con todo recogimiento". Por tal motivo solicitaba "se le embarguen los bienes y (sea) condenado en pena capital por quebrantamiento"13.

El marco jurídico de la época establecía penas muy severas para el delito de estupro. Sobre todo porque era un "pecado contra la castidad". Según las Partidas del Rey Alfonso el Sabio, las faltas en esta materia eran muy graves porque

Castidad es una virtud que ama Dios y deben amar los hombres. Según dijeron los sabios antiguos, tan noble y tan poderosa es su bondad, que ella sola cumple para presentar las ánimas de los hombres y de las mujeres castas ante Dios. Y yerran muy gravemente aquellos que corrompen a las mujeres (...) siendo vírgenes ${ }^{14}$.

Sobre la base de concebir la castidad de la mujer como valor absoluto, los españoles construyeron un edificio jurídico sumamente riguroso para castigar a aquellos hombres que hacían el amor con mujeres vírgenes sin estar casados con ellas. No importaba si el acto se consumaba por fuerza o con el consentimiento de la mujer. El varón tenía prohibido unirse físicamente a ella. Las Partidas lo manifestaban con claridad:

Hacen gran maldad aquellos que seducen con engaño, halago o de otra manara, a las mujeres vírgenes o las viudas que son de buena fama y viven honestamente (...). No se puede excusar el que yaciere con alguna mujer de éstas, que no cometió una gran falta, aunque diga que lo hizo con el placer de ella, sin forzarla. Esto, según dicen los sabios antiguos, como en manera de fuerza es convencer y halagar a las mujeres con promesas vanas, haciéndoles hacer maldad de sus cuerpos. Y aquellos que lo hacen de esta manera, más yerran que si lo hiciesen por fuerza ${ }^{15}$.

La gravedad que se le atribuía al acto de hacer el amor con una mujer virgen o viuda se fundamentaba en el particular enfoque de la doctrina católica sobre el sexo y el cuerpo. Si el cuerpo era el templo del Espíritu Santo, una profanación de ese cuerpo era un acto cercano a un sacrilegio. Además, si la gravedad de una ofensa se mide por la dignidad del ofendido, siendo el

\footnotetext{
${ }^{13}$ Juicio contra Juan de Puebla Reinoso por estupro, Santiago, 14 de abril de 1633 . AN, Real Audiencia, volumen 3.031, fols. 37-37 v.

${ }^{14}$ Partida VII, título XIX. Los códigos españoles concordados y anotados. Código de las Siete Partidas (Madrid, Antonio de San Martín editor, 2 edición, 1872): tomo IV, p. 420.

${ }^{15}$ Partida VII, título XIX, ley I. Los códigos españoles...: tomo IV, p. 420.
}

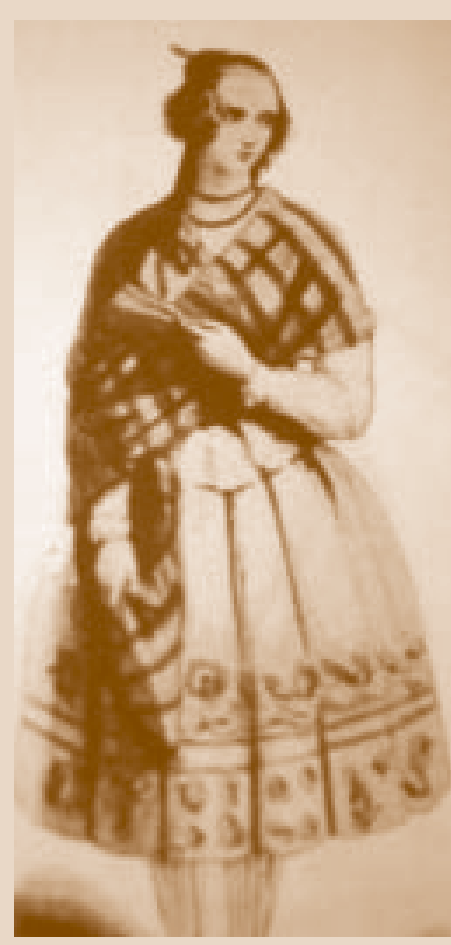




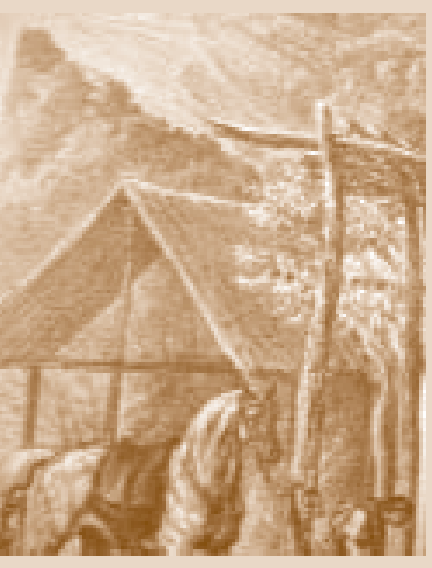

pecado contra la virtud de la pureza un agravio a Dios, cuya dignidad es infinita, la gravedad de esta falta también lo era. Con más razón si con este acto el varón arrastraba a pecar a una mujer y la corrompía. Dada la gravedad de este delito, las penas eran muy severas. En efecto, las Partidas establecían que

Si aquel que lo hiciere fuese hombre honrado, puede perder la mitad de todos sus bienes y deben ser de la Cámara del Rey. Y si el hombre fuese vil debe ser azotado públicamente y desterrado a alguna isla por cinco años. Pero si fuese siervo o sirviente de la casa, aquel que sedujere o corrompiere alguna de las mujeres sobredichas, debe ser quemado ${ }^{16}$.

La aplicación de estos criterios en el caso de Juan de Puebla era muy clara: por tratarse de un personaje de la elite socioeconómica cuyana, debía ser castigado con la confiscación de la mitad de sus bienes. En este sentido, el reclamo de doña Teodora era muy preciso: "pido que entre los bienes (que se le) demandasen en cargas sean los tributos de los indios de dicho Juan de Puebla Reinoso y que la persona los pueda sacar de donde quiera que estén y hacerse cargo para los ir alquilando y para dar con pago cada cuando se le pida" 17 . Por pertenecer a una familia de encomenderos, ella sabía del alto valor que tenía la mano de obra indígena en el mercado. Los indios eran muy pocos en Mendoza, pues la mayor parte había sido trasladada por la fuerza hacia Santiago de Chile, a las minas de La Serena y otros puntos para prestar sus servicios. La población huarpe mendocina fue diezmada entre las últimas décadas del siglo XVI y las primeras del XVII. En este contexto, las escasas encomiendas que aún contaban con una dotación de indios eran bienes muy cotizados. Precisamente en este contexto, doña Teodora consideró que la "afrenta” que había sufrido su familia tenía en esas encomiendas la mejor forma de satisfacción.

Además de la pena de carácter económico, doña Teodora solicitó que se condenara a muerte a don Juan. Este pedido no se encuadraba tan claramente en las Siete Partidas. Pero a la vez, la demandante podía alegar agravantes debido a la proximidad entre el ofensor y la familia de la "víctima". Don Juan de Puebla no era sirviente de la casa de doña Teodora Castañeda; pero había fuertes lazos de confianza entre ambos. Al parecer, la mujer buscó argumentos para fundamentar a la vez el reclamo de resarcimiento económico y de pena capital.

La justicia falló en todo de acuerdo con lo solicitado por doña Teodora.

\footnotetext{
${ }^{16}$ Partida VII, título XIX, ley II. Los códigos españoles...: tomo IV, p. 421

${ }^{17}$ Juicio contra Juan de Puebla Reinoso por estupro, Santiago, 14 de abril de 1633. AN, Real Audiencia, volumen 3.029, fols. 209.
} 
La Real Audiencia condenó a Juan de Puebla a efectuar un oneroso pago en dinero: le ordenó abonar la suma de $\$ 10.000$, mitad por costos judiciales y mitad como dote para la mujer ultrajada. Nótese lo elevado que resultaba esa cifra: un siglo más tarde, el empresario más rico de Mendoza poseía bienes por $\$ 32.000^{18}$.

Junto con las compensaciones económicas, doña Teodora logró un castigo ejemplar para el amante de su hija. La Real Audiencia hizo lugar a sus demandas y llegó a una sentencia terrible: Juan de Puebla fue condenado a muerte. En efecto, por Real Provisión del 21 de abril de 1635 se ordenó "que en el lugar en donde pudiese ser habido, sea preso y llevado a la cárcel de la dicha ciudad de Mendoza, y de ella sea sacado en forma de justicia por las calles acostumbradas de dicha ciudad y en la plaza de ella esté puesta una horca en la cual sea ahorcado hasta que naturalmente muera"19. Para noticia de todo el pueblo, la orden de detención contra Puebla fue comunicada públicamente por pregón de tres en tres días.

La decisión de la Real Audiencia tuvo notas de energía. Se ordenó que "donde quiera que fuese hallado y pudiese ser habido, lo prendiesen con sus bienes; y con las prisiones y guardas necesarias lo remitiesen a la cárcel de la Real Audiencia (para) ejecución de la dicha sentencia de muerte"20. El organismo recomendó "prendan y hagan prender a Juan de Puebla y, preso a buen recaudo con las provisiones y guardias que convengan, y con sus bienes sean llevados a la cárcel de la Audiencia para que se ejecute la sentencia de muerte. Y los bienes se pudieran traerlos y vender y rematar en almoneda, procedido por inventario jurídico" ${ }^{21}$. La sentencia de muerte debía aplicarse "sin excusa ni dilación". Y se responsabilizaba al Justicia Mayor, "so pena de mil pesos" 2 . Además, se estableció un incentivo para los que capturasen al reo: "a los guardias que trajeren al dicho Juan de Puebla se les pagarán (...) un mil pesos de bueno oro"23.

El medio dispuesto para implementar la pena de muerte también resulta notable. De acuerdo a los usos y costumbres de la sociedad colonial, al menos en las provincias del Río de la Plata, la forma de matar al culpable varia-

\footnotetext{
${ }^{18}$ Juicio contra Juan de Puebla por estupro. Santiago, 14 de abril de 1633. AN, Real Audiencia, volumen 3.029 , fs 207 ss.

${ }^{19}$ Juicio contra Juan de Puebla por estupro. Real Provisión, Santiago, 21 de abril de 1635. AN, Real Audiencia, volumen 3031, fs 38-38 v. Espejo, o.c., tomo I, pp. 92-93.

${ }^{20}$ Sentencia de la Real Audiencia, Santiago de Chile, 21 de abril de 1637. AN, Real Audiencia, volumen 3.031, fols. 38 .

${ }^{21}$ Sentencia de la Real Audiencia, Santiago de Chile, 21 de abril de 1637. AN, Real Audiencia, volumen 3.031, fols. 38-38 v.

${ }^{22}$ Juicio contra Juan de Puebla Reinoso por estupro, fecha ilegible. AN, Real Audiencia, volumen 3.029 , fols. $210 \mathrm{v}$.

${ }^{23}$ Sentencia de la Real Audiencia, Santiago de Chile, 21 de abril de 1637. AN, Real Audiencia, volumen 3.031, fols. 38-38 v.
}

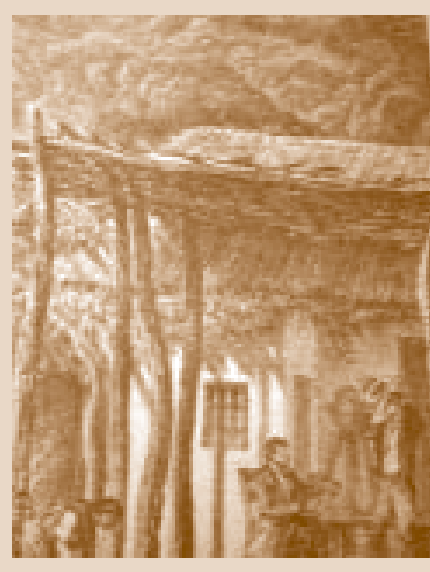




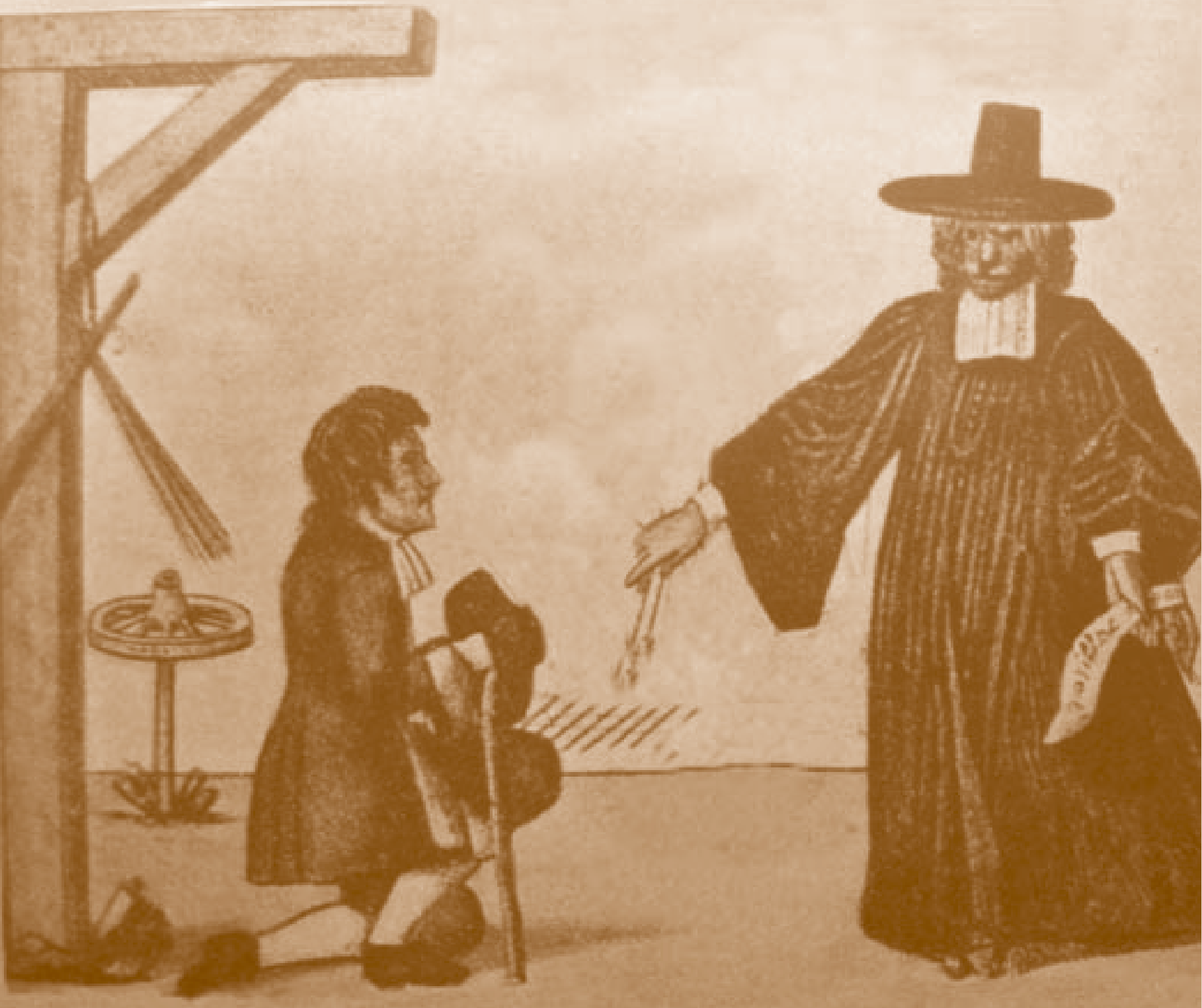


ba según su "calidad social". Los miembros de las élites recibían un tratamiento preferencial, en tanto que la "gente vil" era objeto de prácticas consideradas más infamantes. Y una de ellas era, precisamente, la horca. En el caso estudiado se produjo la paradoja de condena a muerte en la horca a un miembro de la élite: una persona que pertenecía al cabildo, y que poseía una de las fortunas más grandes de la región. El motivo de este tratamiento anómalo se encuentra en la naturaleza de la falta cometida. Evidentemente, la sociedad colonial tenía una particular percepción del significado de la vida sexual y toda desviación de lo que se considerara canales legítimos para esta dimensión de la vida humana, significaba un escándalo que debía ser reprimido con la mayor energía posible.

\section{LA GRACIA DEL PERDON DIVINO}

Para asombro de la comunidad mendocina, don Juan de Puebla y Reinoso obtuvo la gracia del perdón. A pesar de la sentencia de la Real Audiencia de Chile, el joven capitular no murió en la horca en 1634. Superó este incidente y vivió casi medio siglo más. Recién falleció en 1678, tras una vida signada por el éxito económico y una destacada carrera política; también tuvo el don de gozar de una numerosa familia de nueve hijos que lo acompañó en sus años otoñales. La pregunta es, ¿ cómo hizo don Juan de Puebla y Reinoso para salvarse de la horca? No huyó a las montañas sino que permaneció en Mendoza, al alcance de cualquier justicia; tampoco se ocultó hasta que su pena prescribiera, normativa que no tenía vigencia en ese tiempo en América colonial. Al parecer, tampoco tuvo chances de obtener el indulto del Rey, única autoridad con atribuciones de revocar la sentencia ${ }^{24}$. Pero era muy excepcional el uso de estas facultades. Por ejemplo, el día más propicio para ello era el Viernes Santo, en el cual, el monarca adhería al ejemplo de infinita misericordia divina para perdonar a algunos reos. Pero esta situación sólo se daba en contados casos pues "el indulto por Viernes Santo no había de beneficiar, según Juan II, a más de veinte reos cada año" (Tomás y Valiente, 1969: 402). Si era difícil obtener el indulto real para los reos peninsulares, para los americanos era casi imposible.

Los condenados a morir en la horca tenían la posibilidad de recibir el perdón por gracia divina. La situación no era muy cómoda para las autoridades pues iba rodeada de un alboroto popular. Según el citado De las Heras Santos, "ordinariamente el alboroto se provocaba cuando la cuerda fatal se rompía de una forma más o menos casual, pues existía la creencia popular

\footnotetext{
${ }^{24}$ Partida VII, 32, 1.
} 
de que el instrumento del suplicio se rompía por voluntad de Dios, en cuyo caso el reo debía ser liberado" (De las Heras, 1991: 321). En efecto, cuando la cuerda se rompía o el mecanismo, por alguna razón, no funcionaba, se consideraba que allí había una intervención divina directa. Cuando el reo, una vez colgado, caía al suelo por rotura de la soga, se producía una reacción colectiva intensa: al grito de “iperdón!, iperdón!”, el público se abalanzaba sobre la víctima, le aflojaba el dogal y le ayudaba a reestablecerse. Y las autoridades consentían, pues, ¿quién se atrevería a cuestionar los insondables designios de la Santísima Providencia? Este fue el caso, por ejemplo, de Francisco Escobar, el primer reo de los anales de la historia del Reino de Chile. El conquistador Pedro de Valdivia lo condenó a la horca por delito de conspiración e intento de asesinato. Pero cuando se intentó ejecutar la sentencia, apareció la mano de Dios, pues "habiéndose cortado la soga de la horca en el momento de la ejecución, el General, según una costumbre usada en su tiempo en casos semejantes, perdonó a ese infeliz"(Barros Arana, 2002: 1, 175). Como la intervención divina estaba fuera de duda, el hombre experimentó un vuelco interior y resolvió dedicar sus días a la contemplación divina en un convento franciscano (Barros Arana, 2000: 1, 175; Díaz, 1925: 155-156).

Aunque no se ha hallado evidencia documental que lo pruebe, lo más probable parece ser que don Juan de Puebla y Reinoso, igual que Francisco Escobar y tantos otros, salvó su vida a los pies del patíbulo, perdonado por la Gracia de Dios. A partir de entonces, el curso de su vida cambió. Terminaron para siempre las persecuciones judiciales. Sus negocios prosperaron, lo mismo que su vida social y política. Don Juan quedó habilitado nuevamente para desenvolverse con total tranquilidad en el Corregimiento de Cuyo, con plenas facultades para la vida económica, social y política.

\section{LA VIDA DESPUES DE LA MUERTE}

Después de obtener el perdón, la vida de don Juan de Puebla se encarriló intensamente hacia los negocios. Durante medio siglo cumplió una activa tarea en el espacio comercial, transportista e industrial de la provincia de Cuyo. El perdón le reestableció plenamente su buen nombre y honor.

Un indicador de la recuperación del prestigio de don Juan de Puebla fue su boda. El perdón alcanzado le permitió contraer matrimonio con una dama de buena posición. En efecto, don Juan se casó con doña Inés Cortés y Acevedo, la cual aportó al matrimonio una dote de $\$ 1.200^{25}$. Ella era una

\footnotetext{
${ }^{25}$ Carta de obligación del capitán Juan de Puebla Reinoso, Mendoza, 16 de diciembre de 1667. AHM, Epoca Colonial, Testamentaria, Carpeta 265, Documento Nº 3, fols. $114 \mathrm{v}$.
} 
mujer dinámica y emprendedora. Cuando su marido estaba ausente debido a sus viajes en las carretas, doña Inés asumió la responsabilidad del hogar y la libertad que ello implicaba. En este contexto no dudó en tomar medidas originales para la época. Así por ejemplo, tuvo la iniciativa de abrir su propia pulpería, lo cual se convirtió en un caso de liderazgo para otras mujeres (leading case). Su ejemplo fue observado e imitado luego por sus pares y ello contribuiría, con el tiempo, a hacer de Chile uno de los reinos con mayor participación femenina en las empresas de este tipo. Así por ejemplo en México, sobre un total de 221 pulperías registradas en 1781, los mujeres controlaban 13; en 1804, sobre 285, las mujeres poseían 17 (6\%). Ello llevó a Silva Riquer a concluir que "el comercio de pulpería no era una actividad en que las mujeres citadinas se interesaran, o no se les permitía su inversión" (Silva, 2001: 273). En el Reino de Chile, en cambio, sobre un total de 117 pulperías registradas en 1776, las mujeres controlaban 24 (20\%) (Andaur, 2005). Todavía no se han estudiado a fondo las causas de esta situación; pero entre ellas fueron importantes los casos de liderazgo, realizados por mujeres que abrieron el camino y luego fueron imitadas por las demás. Entre estos leading cases se encuentra, precisamente, doña Isabel, la esposa de don Juan de Puebla.

La confianza que los mendocinos le dispensaron del capitán Juan de Puebla Reinoso, después de la gracia recibida, fue clara y franca. Tal como refleja el Cuadro I, don Juan fue recurrentemente elegido como tasador de bienes, testigo de operaciones comerciales, garante de créditos y como albacea testamentario. Así por ejemplo, en 1666 fue tasador de los bienes del capitán Alonso Gallardo ${ }^{26}$. Más tarde, en 1673 se le confió la tasación de los bienes de doña Angela Videla, cuyas propiedades tenían un valor cercano a los $\$ 3.000^{27}$. Muchas veces se le pidió que actuara como testigo: ello sucedió en el crédito de $\$ 468.4$ reales que el capitán Juan Moyano de Aguilar se comprometió a pagar a Francisco Alvarez de Toledo (1647) ${ }^{28}$; en el Codicilio del padre Alonso de Reinoso y Robles $(1647)^{29}$; en el poder para testar de

\footnotetext{
${ }^{26}$ Inventario de bienes del capitán Alonso Martínez Gallardo, Mendoza, 28 de noviembre de 1666. AHM, Protocolo de Escribanos N 18, fols. 96.

${ }^{27}$ Nombramiento de Juan de Puebla Reinoso como tasador de los bienes de Angela Videla, Mendoza, 18 de diciembre de 1673. AHM, Protocolo de Escribanos $N^{\circ} 20$, fols 49 v. - 51. Inventario de bienes de Angela Videla, Mendoza, 16 de diciembre de 1673. AHM, Protocolo de Escribanos $\mathrm{N}^{\circ} 20$, fols 49-51 v.

${ }^{28}$ Carta del capitán Juan Moyano de Aguilar, Mendoza, 18 de junio de 1647. AHM, Protocolo de Escribanos $\mathrm{N}^{\circ} 13$, fols 26.

${ }^{29}$ Codicilio del padre Alonso de Reinoso y Robles, Mendoza, 6 de noviembre de 1647. AHM, Protocolo de Escribanos $\mathrm{N}^{\circ} 13$, fols. 70-71.
} 


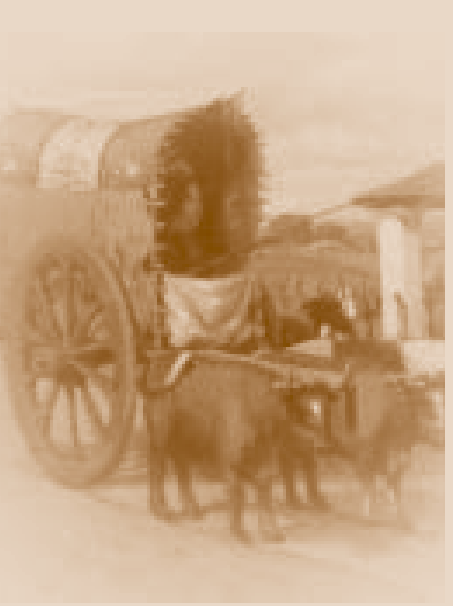

Sebastián López de Vargas $(1657)^{30}$, en la tasación y partición de bienes de Juan de Roa $(1663)^{31}$, en el poder dado por Luisa Reinoso $(1669)^{32}$, y en el testamento de Juan López de Villarroel (1666) ${ }^{33}$. En otra oportunidad don Juan prestó fianza por $\$ 700$ a Domingo Zapata $(1649)^{34}$. Paralelamente, el capitán fue elegido como albacea testamentario de otros vecinos, entre ellos doña María Magdalena de Videla y Jufré (1647), de doña Juana de Vega Sarmiento $(1669)^{35}$. Don Juan de Puebla fue también albacea testamentario de muchos familiares directos. Entre ellos podemos citar a su hija Beatriz $(1666)^{36}$, su hermano Jacinto $(1666)^{37}$ y su esposa doña María del Castillo y Figueroa $(1669)^{38}$. Estos últimos casos demuestran que don Juan de Puebla y Reinoso logró establecer una familia estable y sostenerla en el tiempo: en el momento de testar su hija y su mujer, don Juan de Puebla seguía junto a ellas y merecía toda la confianza como para ser nombrado su albacea testamentario.

El transporte comercial de cargas fue una de las actividades principales de don Juan de Puebla. En efecto, en la década de 1640 administró una tropa de diez carretas. Esta era la mayor empresa de transporte de Mendoza donde, en esos años, prestaban servicios entre 45 y 50 carretas $^{39}$. Para avanzar en esta dirección, don Juan estableció una serie de contratos con el sargento mayor don Francisco Alvarez de Toledo, para obtener las carretas. En 1648 don Juan de Puebla adquirió a crédito, a un valor de \$330, "seis carretas con cargas de vino con veinte botijas cada una y sus ocho bueyes, los cuales no se venderán ni pasarán a poderío ajeno si no es para efecto de

${ }^{30}$ Poder para testar de Sebastián López de Vargas, Mendoza, 21 de junio de 1657. AHM, Protocolo de Escribanos $N^{\circ} 17$, fols. 46.

${ }^{31}$ Petición del tenedor de los bienes de Juan de Roa, Mendoza, 20 de noviembre de 1663. AHM, Protocolo de Escribanos $N^{\circ} 17$, fols. 36.

${ }^{32}$ Poder dado por doña Luisa Reinoso, Mendoza, 3 de setiembre de 1669. AHM, Protocolo de Escribanos $\mathrm{N}^{\circ} 19$, fols $101 \mathrm{v}$., $102 \mathrm{v}$.

${ }^{33}$ Testamento de Juan López de Villarroel, Mendoza, 20 de octubre de 1666. AHM, Protocolo de Escribanos $\mathrm{N}^{\circ} 18$, fols. 83.

${ }^{34}$ Fianza de Juan de Puebla Reinoso, Mendoza, 13 de enero de 1649. AHM, Protocolo de Escribanos $\mathrm{N}^{\circ} 15$, fols. 7 .

${ }^{35}$ Codicilio de Juana de Vega Sarmiento, 13 de febrero de 1669. AHM, Protocolo de Escribanos $\mathrm{N}^{\circ} 19$, fols. 128 .

${ }^{36}$ Inventario de bienes de Beatriz de Puebla Reinoso, Mendoza, 6 de marzo de 1666. AHM, Protocolo de Escribanos $\mathrm{N}^{\circ} 18$, fols. 17.

${ }^{37}$ Poder para testar del capitán Jacinto de Puebla Reinoso, Mendoza, 18 de marzo de 1666. AHM, Protocolo de Escribanos $N^{\circ} 18$, fols 25.

${ }^{38}$ Testamento de María Magdalena de Videla y Jufré, Mendoza, 27 de noviembre de 1647. AHM, Protocolo de Escribanos $\mathrm{N}^{\circ} 13$, fols. 81-83. Declaración del alcalde don Francisco Chirinos de Posada, Mendoza, 13 de febrero de 1669. AHM, Protocolo de Escribanos $N^{\circ}$ 19, fols. 127; Poder para testar de doña María del Castillo y Figueroa, Mendoza, 8 de octubre de 1669. AHM, Protocolo de Escribanos $\mathrm{N}^{\circ} 19$, fols 112-113.

${ }^{39}$ AHM, Protocolo de Escribanos $N^{\circ} 16$ fols. 15. Luis Coria, Evolución económica de M endoza en la época colonial (Mendoza: Universidad Nacional de Cuyo, 1988): 70. 
Cuadro I. Actos jurídicos del capitán Juan de Puebla y Reinoso (Mendoza, 16471673).

\begin{tabular}{|c|c|c|c|c|}
\hline Año & Testigo de & $\begin{array}{l}\text { Tasador de } \\
\text { bienes de }\end{array}$ & Fiador de & $\begin{array}{l}\text { Albacea } \\
\text { testamentario de }\end{array}$ \\
\hline 1647 & $\begin{array}{l}\text {-Juan de Moyano } \\
\text { y Aguilar } \\
\text {-Alonso de Reinoso } \\
\text { y Robles }\end{array}$ & & & $\begin{array}{l}\text {-María Magdalena } \\
\text { de Videla y Jufré }\end{array}$ \\
\hline 1649 & & & $\begin{array}{l}\text {-Domingo } \\
\text { Zapata }\end{array}$ & \\
\hline 1657 & $\begin{array}{l}\text {-Sebastián López } \\
\text { de Vargas }\end{array}$ & & & \\
\hline 1663 & -Juan de Roa & & & \\
\hline 1666 & $\begin{array}{l}\text {-Juan López de } \\
\text { Villarroel }\end{array}$ & -Alonso Gallardo & & $\begin{array}{l}\text {-Beatriz de Puebla } \\
\text {-Jacinto de Puebla } \\
\text { y Reinoso }\end{array}$ \\
\hline 1669 & -Luisa Reinoso & & & $\begin{array}{l}\text {-Juana de Vega } \\
\text { Sarmiento } \\
\text {-María del Castillo } \\
\text { Figueroa }\end{array}$ \\
\hline 1673 & & -Angela de Videla & & \\
\hline
\end{tabular}

Fuente: AHM, Protocolo de Escribanos; Alicia Virginia Gabbi y Elvira Martín de Codoni, M endoza en sustestamentos, siglos XVI, XVII y XVIII (Mendoza: Facultad de Filosofía y Letras de la Universidad Nacional de Cuyo, 1996).

dicho pago" ${ }^{40}$. Don Francisco le otorgó, además, un crédito por \$529 con 1 real para sus operaciones comerciales ${ }^{41}$.

La hacienda de don Juan de Puebla y Reinoso se nutrió del trabajo de esclavos e indios. Entre ellos estaban "dos indios, uno Lorenzo, natural de Santiago del Estero, y el otro Pablo, natural de La Rioja”, los cuales "de su voluntad quieren servir al capitán Juan de Puebla y Reinoso". En el documento labrado para formalizar este contrato, se estipuló que "se les ha de pagar su salario a razón de \$4 por mes y cuidarlos de enfermedades” ${ }^{42}$. Los esclavos africanos también estaban presentes en las propiedades de don Juan.

\footnotetext{
${ }^{40}$ Carta de Obligación de Juan de Puebla Reinoso, vecino feudatario de Mendoza, Mendoza, 9 de noviembre de 1648. ANM, Protocolo de Escribanos $\mathrm{N}^{\circ} 14$, fols. 59.

${ }^{41}$ Carta de Obligación de Juan de Puebla Reinoso, vecino feudatario de Mendoza, Mendoza, 9 de noviembre de 1648. ANM, Protocolo de Escribanos $\mathrm{N}^{\circ} 14$, fols. 85.

${ }^{42}$ Carta de servicio indígena, Mendoza, 28 de octubre de 1647. AHM, Protocolo de Escribanos $\mathrm{N}^{\circ} 13$, fols. $61 \mathrm{v}$.
} 


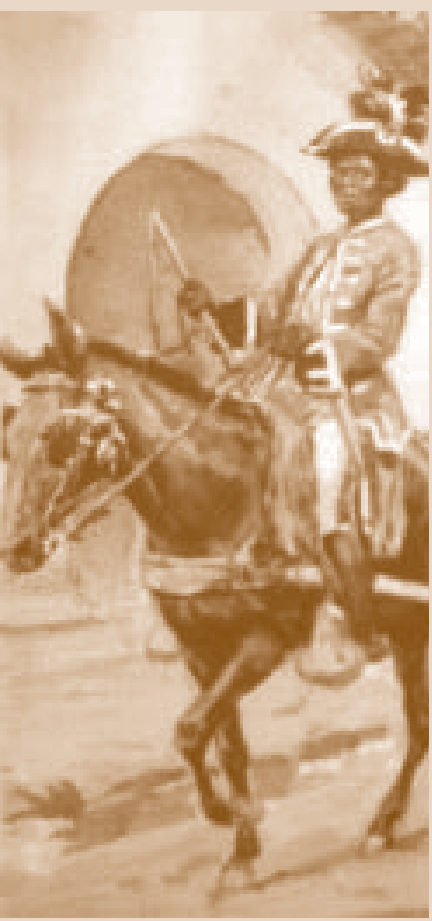

Así quedó documentado en la venta de una esclava que se concretó con motivo de la muerte de su esposa en 1668. La negra fue vendida en $\$ 380^{43}$.

La prosperidad de los negocios de don Juan de Puebla le permitió ceder generosas dotes a sus hijas y fortalecer la presencia de su linaje en el centro del espacio socioeconómico colonial. La dote de María Puebla y Castilla, al casarse con el sargento mayor Pedro Correas (1679) fue un buen ejemplo de su prosperidad económica. Según la Carta de Dote, ella recibió cuatro esclavos, "un negro llamado Pedro, de 24 años de edad, botijero, en \$600; una mulata llamada Leonor, 30 años, en \$450; una mulatilla María de 11 a 12 años en \$300; un mulatillo de 9 a 10 años, Marcelo, en \$300”. En total los esclavos valían $\$ 1.650$. Además, la mujer recibió "una casa de vivienda cuya puerta cae enfrente de la huerta de la Compañía de Jesús por la parte del poniente con todo el edificio que de el patio principa de allí en las tierras de norte y oriente del el mismo y mitad de la huerta, en $\$ 600$ ". La dote incluía también joyas como "trece marcos de plata labrada de una onza a $\$ 7$ el marco; dos candelabros con 4 marcos de cinco onzas a razón de \$9 el marco; por todo: $\$ 133$ y 4 reales". A ello se agregaron "9 cuadras de tierra para chacra en la que tienen poblada al oriente de esta ciudad en $\$ 30$; una caja grande en $\$ 30$, un pabellón de cordoncillo labrado aquí, en $\$ 30$; un vestido en $\$ 50$, un escritorio en $\$ 20$ ” y una bodega en la cual había “200 @ de vino en $\$ 400$ "; el tercer grupo de bienes representaba $\$ 560$. El valor total de la dote ascendía a $\$ 2.943$ con 4 reales ${ }^{44}$. Teniendo en cuenta que la beneficiaria de esta dote fue uno de los nueve hijos legítimos de don Juan de Puebla y Reinoso, se puede estimar la magnitud de sus bienes: éstos rondarían los $\$ 30.000$.

La recuperación económica que logró don Juan fue notable; y no tardaría en alcanzar también el retorno al poder político. En efecto, durante la gestión de don Juan de Roa al frente de Cuyo (1661-1663), Puebla fue teniente de corregidor y Justicia Mayor (Morales, 1936: 63). Después de treinta años, don Juan de Puebla regresaba al Cabildo de Mendoza, revestido con los cargos de mayor jerarquía y prestigio social.

\section{DON JUAN Y LA INDUSTRIA DEL VINO}

Don Juan de Puebla Reinoso se dedicó con éxito al cultivo de la viña y a la elaboración del vino. Sus bodegas almacenaban al menos 700 @ de vino ${ }^{45}$,

\footnotetext{
${ }^{43}$ Carta de venta, Mendoza, 9 de enero de 1668. AHM, Protocolo de Escribanos $N^{\circ} 19$, fols 1-4.

${ }^{44}$ Herederos de don Juan de Puebla Reinoso contra doña María del Castillo sobre la división de sus bienes, Santiago, 17 de octubre de 1691. AN, Real Audiencia, volumen 1.705, 250-251.

${ }^{45} \mathrm{La}$ arroba (@) era la unidad empleada como unidad de medida para los líquidos. En Cuyo se usaba la arroba de 35,55 litros.
} 
lo cual significaba un capital de $\$ 1.400^{46}$. Este oficio era, en realidad, una antigua tradición familiar. El abuelo de su madre (doña Beatriz de Reinoso) fue el maestro de campo don Alonso de Reinoso, el cual, hacia 1580, poseía una viña de 5.000 plantas y una bodega con capacidad para 155 arrobas de vino (Lacoste, 2003: 114). No fue casualidad que don Juan recibiera como herencia una viña en la ciudad, la cual cultivó y mantuvo a lo largo de toda su vida. Era una viña pequeña, de unas 3.000 plantas $^{47}$. Los vinos que elaboró adquirieron prestigio y fueron solicitados como medio de pago para saldar deudas. Así se verificó, por ejemplo, en la devolución de la dote de doña Isabel a su hermano, don Ignacio de Acevedo. En efecto, a mediados de la década de 1670, don Juan de Puebla Reinoso reconoció que era

deudor de \$1.200 en plata corriente al capitán don Ignacio de Acevedo por razón del dote que se me dio cuando casé con doña Isabel Acevedo, su hermana, en primer matrimonio, ya difunta, por pertenecerle al dicho capitán don Ignacio de Acevedo como legítimo heredero ${ }^{48}$.

Para saldar esta deuda, don Juan abonó primeramente \$112; luego se comprometió a pagar otros $\$ 587.4$; los restantes $\$ 500$ se abonarían directamente en "vino bueno". Así se acordó en un contrato comercial celebrado el 29 de diciembre de 1673, en el cual don Juan de Puebla se comprometió a entregar

$200 @$ de vino bueno en 80 botijas que han de ser bien cocidas y bien breadas de modo que no tengan merma por mal cocidas y breadas, y que las ha de entregar por todo el mes de agosto a setiembre del año venidero de 1674. Si al plazo señalado no hubiere llegado el dicho don Ignacio de Acevedo, se obliga Juan de Puebla a tenerlo embotijado y tapado con yeso en su bodega (...). Las dichas 200 @ de vino las ha de recibir don Ignacio a dos patacones arroba que hacen $\$ 400$ de a ocho reales y las 80 botijas de a 10 reales que es el corriente de la tierra, que montan $\$ 100$.

\footnotetext{
${ }^{46}$ Entre los bienes de don Juan de Puebla Reinoso transferidos a sus hijos figuran por un lado $200 @$ de vino, y por otro 500 @. Herederos de don Juan de Puebla Reinoso contra doña María del Castillo sobre la división de sus bienes, Santiago, 17 de octubre de 1691. AN, Real Audiencia, volumen 1.705 , fols 246 y $250-251$.

${ }^{47}$ Esta viña fue hipotecada "para que en ella se haga la ejecución, venta y remate en caso de que falta de hacer la paga" de \$1.200 que don Juan de Puebla Reinoso tenía que hacer a su ex cuñado don Ignacio de Acevedo (Contrato de hipoteca de Juan de Puebla Reinoso, Mendoza, 29 de diciembre de 1673. AHM, Epoca Colonial, Testamentaria de Juan de Puebla Reinoso y María del Castillo, Carpeta 265, Documento 3, fols. 117). Por lo tanto, la viña no podía exceder en mucho este valor, de lo cual se desprende que no podía tener más de 3.000 plantas.

${ }^{48}$ Carta de obligación de Juan de Puebla Reinoso, Mendoza, 16 de diciembre de 1667. AHM, Epoca Colonial, Testamentaria de Juan de Puebla Reinoso y María del Castillo, Carpeta 265, Documento 3, fols. $114 \mathrm{v}$.
}

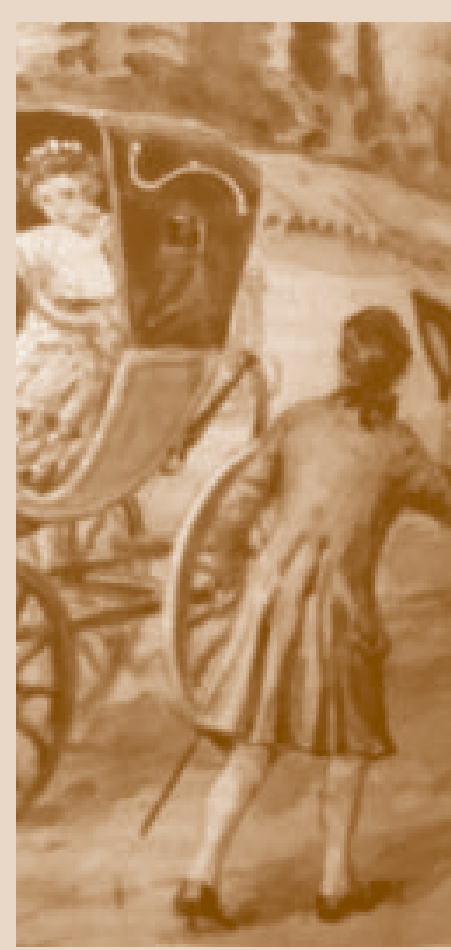


Junto con el valor del vino son $\$ 500$. Y si las 80 botijas las diere esteradas, se entiende las ha de llevar por 12 reales la botija ${ }^{49}$.

El documento es revelador de las técnicas que se usaban para la manipulación de los vinos. Las botijas eran embreadas, tapadas con yeso y luego esterilladas para evitar que se rompieran en los viajes en carreta a Buenos Aires. Llama la atención el esmero de los contratantes para cuidar delicadamente los mecanismos que aseguraran la calidad de la conservación y traslado de los vinos.

La bodega de don Juan de Puebla Reinoso fue una de las primeras del Cono Sur que se especializó en elaborar buenos vinos. La pregunta es ¿por qué? ¿Cuál era el interés del capitán por desarrollar vinos de calidad? Por un lado, podía haber un móvil económico: el vino bueno tenía mayor valor en el mercado. Pero también hubo motivos religiosos. En el marco de una sociedad empapada de un intenso espíritu religioso, don Juan quería ganarse el cielo y la vida eterna. Para ello debía ganarse el favor de la misericordia divina, lo cual se lograba con la ayuda de los frailes de los conventos, cuyas oraciones y misas podían tener un efecto altamente grato a los ojos de Dios. Y el vino era el medio más adecuado para alcanzar estos objetivos.

Había una conexión entre el vino y la vida eterna. En su testamento, don Juan de Puebla dispuso que se destinaran $50 @$ de vino al convento de Santo Domingo para que, a cambio, los frailes se ocuparan de la salud de su alma. Con sus misas, rezos y mortificaciones los religiosos podían aliviar los atroces sufrimientos que debían padecer antes de ponerse en condiciones de presentarse en la presencia de Dios. La utilidad de las oraciones de los vivos por el alma de los muertos estaba fuera de discusión en la Iglesia Católica a partir del Concilio de Florencia (1431). Más tarde, el Concilio de Trento ratificó esta noción (1563). Y los españoles expandieron estas ideas en todos su imperio, incluyendo el lejano Reino de Chile. En el caso de don Juan de Puebla, lo relevante es que se intentó alcanzar el favor divino a través del vino. Y del vino de calidad. Así, por ejemplo, fray Miguel Rodríguez de Luján, capellán del convento de Santo Domingo, extendió un recibo a nombre del capitán Juan de Godoy, albacea testamentario de don Juan de Puebla, en el cual mencionaba el tema de la calidad:

Señor Capitán Juan de Godoy:

El tesorero, don Antonio Peredo, me ha acomodado embotijada cantidad de los \$37.4 que los herederos del señor capitán Juan de Puebla,

\footnotetext{
${ }^{49}$ Contrato de hipoteca de Juan de Puebla Reinoso, Mendoza, 29 de diciembre de 1673. AHM, Epoca Colonial, Testamentaria de Juan de Puebla Reinoso y María del Castillo, Carpeta 265, Documento 3, fols. 115, v. 116.
} 
difunto, pagara a este convento. Sírvase Vuestra Merced de que se le hagan buenos vinos a dicho tesorero que con su recibo lo haré buenos en el libro del convento y yo recibiré merced que Dios a Vuestra Merced como ese este su hermano y capellán.

Fray Miguel Rodríguez de Luján ${ }^{50}$

El objetivo principal de esta nota era documentar la recepción de las botijas de vino en la bodega del convento. Pero se aprovecha la oportunidad para solicitar que se ponga énfasis en la tarea. La redacción no es clara pero insinúa que el capellán sabrá valorar la calidad del vino, y está dispuesto a agradecerla con su tarea en el convento. Y la acción del convento era, fundamentalmente, atraer la mirada y la misericordia de Dios a través de la oración y la mortificación. Poco después se produjo otro documento con sentido similar:

Yo, fray Gabriel de Ojeda, Maestro de Santa Teología de la sagrada Orden de Predicadores, recibí de mano del capitán Juan Godoy del Castillo, vecino de esta ciudad de Mendoza, provincia de Cuyo, 50 @ de vino que me debía del capitán Juan de Puebla Reinoso, difunto, que Dios tenga en su santa gloria, como las declaró por una cláusula de su testamento que hizo en dicha ciudad al tiempo de su fallecimiento ${ }^{51}$.

El vino se convertía en el puente entre lo temporal y lo eterno. Era el camino que permitiría al alma de don Juan de Puebla trascender la muerte, el dolor y las penas del Purgatorio. Era la llave maestra que le abriría las puertas del paraíso. Si su vida se terminaba, el vino quedaría allí, para rescatarlo de la oscuridad y retornarlo a la luz de la vida.

\section{DON JUAN Y SUS DESCENDIENTES}

La reivindicación pública lograda con el perdón, y el éxito económico generado por sus viñas y carretas, abrieron a Juan de Puebla y Reinoso el camino de retorno al poder social y político. En el plano social, después del fallecimiento de su primera esposa, don Juan contrajo enlace con María del Castillo, destacada integrante de la élite colonial de la región, hermana de don

\footnotetext{
${ }^{50}$ Recibo del capellán del convento de Santo Domingo, fray Miguel Rodríguez de Luján, Mendoza, 16 de octubre de 1675. AHM, Epoca Colonial, Testamentaria de Juan de Puebla Reinoso y María del Castillo, Carpeta 265, Documento 3, fols. 104 v.

${ }^{51}$ Recibo de fray Gabriel de Ojeda, Mendoza, 13 de noviembre de 1675. AHM, Epoca Colonial Testamentaria de Juan de Puebla Reinoso y María del Castillo, Carpeta 265, Documento 3, fols. $107 \mathrm{v}$.
} 
Juan de Godoy del Castillo. Con ella tuvo nueve hijos, los cuales establecieron enlaces prominentes.

Una hija de don Juan fue Inés de Puebla. Desposó al peninsular Simón de Lima y Melo, de cuyo tronco surgió una familia de gran trayectoria en el derecho, la política, las armas y la Iglesia. De esta unión nacieron, por ejemplo el presbítero Domingo Lima y Melo y el maestre de campo Eusebio Lima y Melo, alcalde, escribano del cabildo de Mendoza y corregidor de la provincia de Cuyo (1752-1756), padre del presbítero Simón Tadeo de Lima y Melo. El primero de estos religiosos, Domingo de Lima y Melo (1694-1767), fue un destacado miembro de la Compañía de Jesús; en 1723 ya estaba ordenado sacerdote y residía en el colegio jesuita de Mendoza; luego pasó a San Luis donde fue superior de la residencia jesuita local (1742-1745); luego regresó a Mendoza donde fue rector del Colegio de la Inmaculada Concepción (1755-1760) (Verdaguer, 1932: I, 267). Su sobrino, Simón Tadeo de Lima y Melo (1779-1808), fue el párroco de San Luis (1753-1764) y San Juan (1764-1798); posteriormente regresó a Mendoza a cumplir su oficio y terminar sus días (Verdaguer, 1932: I, 404 y 463). Además de su aporte al desarrollo eclesiástico y cultural cuyano, esta familia contribuyó también al progreso de la industria del vino. Don Simón de Lima y Melo dio un nuevo impulso a las propiedades familiares, particularmente en la producción vitivinícola. Durante el tiempo en el cual estuvo como administrador de los bienes familiares, por minoría de edad de cuatro de sus hermanos, don Simón construyó una fábrica de botijas y tinajas. El establecimiento se levantó en las bodegas que habitaba su cuñado Juan de Puebla ${ }^{52}$.

Otra hija de Juan, Petrona Puebla, se casó con el capitán Miguel Torres, hijo de un español peninsular, el capitán Miguel Torres Barros Hinojosa, natural de Jerez de la Frontera; otra hija de don Juan, María Puebla, casó con el sargento mayor Pedro Correas, alcalde de primer voto, teniente de gobernador, justicia mayor y escribano del cabildo de Mendoza.

Uno de los hijos varones de don Juan fue Francisco de Puebla. Nacido en 1758 , fue el mayor de sus hermanos. Acompañó a su padre en la administración de la empresa familiar, en los múltiples negocios que se extendían de Mendoza hacia el resto del reino de Chile, como así también a las provincias rioplatenses. Tras el fallecimiento de su padre, Francisco era todavía menor de 25 años de edad, con lo cual no podía, legalmente, asumir la dirección de los negocios. Por tal motivo, solicitó al alcalde la emancipación y habilitación de edad "para hacer tratos y contratos en esta ciudad como en las pro-

${ }^{52}$ Orden del corregidor para que Juan de Puebla y don Simón de Lima y Melo no tengan litis por la posesión de fábrica de tinajas, Mendoza, 5 de diciembre de 1692. AHM, Carpeta 167 Documento 16. 
vincias de Tucumán, Buenos Aires y Chile, donde estoy en contingencia"53. El alcalde ordinario de Mendoza, capitán Juan de Avila Sanabria, accedió al pedido y le dio la autorización en nombre de su majestad. Habilitado por las autoridades, don Francisco pudo continuar con la tarea encomendada. Además, obtuvo el grado militar de capitán y fue alcalde de segundo voto de Mendoza. Don Francisco engendró una familia llamada a destacarse en la Iglesia y en la industria del vino. En el plano eclesiástico, el aporte se canalizó a través de su hija Josefa de Puebla; desposada con Miguel de Allende, natural de Buenos Aires, engendró a los hermanos Ignacio Antonio (17141794) y Miguel de Allende y Puebla (1716-1794), ambos religiosos de la Compañía de Jesús. Estudiaron en el Colegio Máximo de San Miguel en Santiago de Chile. El padre Ignacio fue coadjutor temporal de la Compañía de Jesús. Su hermano, el padre Miguel, residió en el Colegio de Mendoza (1746-1754), en el cual llegó al cargo de ministro; posteriormente prestó servicios en las casas jesuitas de San Luis y San Juan. Continuó su carrera en Quillota, en el corazón del Valle Central de Chile. Al producirse la expulsión de los jesuitas en 1767, los dos hermanos fueron trasladados a Imola (Italia), donde vivieron los últimos años de sus vidas; de gran valor resultaron los escritos del padre Miguel al Pbro. Ignacio Godoy sobre los principales cursos de agua de Cuyo y el Valle Central (Verdaguer, 1932: I, 386-387).

El lazo de la familia de don Juan de Puebla y Reinoso con la industria vitivinícola regional se realizó a través de sus hijos y nietos. Estos profundizaron los impulsos apasionados de su abuelo: creativo, ambicioso, innovador e indisciplinado. Así lo reflejaron Juan, Juan Martín y Santiago de Puebla, nietos de don Juan ${ }^{54}$. El grado de desarrollo alcanzado por las bodegas y viñedos de Juan Martín, Santiago y Juan de Puebla quedó documentado en sus testamentos (1757, 1757 y 1766, respectivamente). A mediados del siglo XVIII, ellos fueron, después de los jesuitas, los tres mayores viticultores de Mendoza; Santiago tenía 10.000 cepas y 850 @ de capacidad en su bodega; Juan poseía 18.000 plantas de vid y 560 @ de vasija; y Juan Martín tenía 17.000 plantas y $400 @$ de vasija (Lacoste, 2003: 125).

Los Puebla se vieron envueltos en amores, viajes, proyectos y sueños que luego se trasladaron a la industria. Un buen ejemplo fue Juan Martín de Puebla, hijo natural de Juan de Puebla y nieto del protagonista de esta historia. Juan Martín vivió su infancia en San Juan junto a su madre. Tras la muerte de ella, su padre lo recibió en su casa de Mendoza, lo crió hasta llegar a la edad escolar, y posteriormente lo envió a estudiar a Santiago de

\footnotetext{
${ }^{53}$ Emancipación de don Francisco de Puebla Reinoso, Mendoza, 15 de octubre de 1678. AHM, Carpeta 176, Documento 7, fols. 1 y 1 v.

${ }^{54}$ Estos tres nietos de don Juan de Puebla Reinoso eran hijos de Felipe, Juan y Francisco de Puebla respectivamente.
} 
Chile $^{55}$. Tras regresar a Mendoza, Juan Martín introdujo nuevos métodos en la industria del vino, muchos de los cuales compartió con sus primos. Como resultado, entre los tres consolidaron un lugar de liderazgo en la vitivinicultura regional.

\section{LOS “VINOS DE DIOS”}

La vida de Juan de Puebla y Reinoso transcurrió en un inestable equilibrio entre el impulso y la planificación reflexiva. En su juventud transgredió las leyes y fue condenado a la horca. Llegó a mirarse cara a cara con la muerte. Pero alcanzado el perdón, su alma se reveló capaz de contribuir al desarrollo social: don Juan generó un aporte decisivo a la puesta en marcha de la industria de la vid y el vino en una sociedad que, con el tiempo, estaba llamada a liderar la viticultura en América Latina. El caso de don Juan puede ser un buen ejemplo de la capacidad del ser humano para recuperarse y realizar una acción creativa al servicio de la comunidad. Por eso es un alegato contra la pena de muerte. Además, por la forma providencial que tuvo Puebla para salvarse de la pena de muerte, y a la luz del notable resultado que él y sus descendientes alcanzaron en la industria vitivinícola, se revela otra conclusión: los vinos de esta región se ganaron el título de "los vinos de Dios".

\section{REFERENCIAS}

Andaur Marín, Carolina. 2005. "Pulperías en el Reino de Chile", Universum N 20 vol. 2 (Talca, $2^{\text {do }}$ semestre).

Arancibia, Claudia, José Tomás Cornejo y Carolina González. 2003. Pena de muerteen Chile colonial. Santiago: Centro de Investigaciones "Diego Barros Arana" / RIL Editores.

Barros Arana, Diego. [1884] 2000. Historia General de Chile. Santiago, Chile: Editorial Universitaria / Centro Barros Arana.

Coria, Luis. 1988. Evolución económica deM endoza en la época colonial. Mendoza: Universidad Nacional de Cuyo.

De las Heras Santos, José Luis. 1991. La justicia penal delosAustrias en la Corona de Castilla. Salamanca: Universidad de Salamanca.

Díaz Meza, Aurelio. s/f. Crónicas dela conquista (Prólogo de José Toribio Medina, 1925). 4 edición: Santiago-Buenos Aires: Editorial Antártica.

Draghi Lucero, Juan. 1940. "Revelaciones documentales sobre la economía cuyana durante la época colonial", Revista de la Junta de Estudios H istóricos de M endoza, tomo XVI (Mendoza), 1 y 2 trimestre, pp. 247-249.

${ }^{55}$ AHM, Carpeta 176, Documento 45. 
1993. Cartas y documentos coloniales de M endoza. Mendoza: Ediciones Culturales.

García Belsunce, César. 1999. La familia. En: Academia Nacional de la Historia. Nueva historia dela nación argentina. 2. Periodo español siglos XVII y XVIII. Buenos Aires: Planeta.

Lacoste, Pablo. 2003. "Vitivinicultura en Chile trasandino", CLAH R, volume 12, number 2 , spring.

Langue, Frédérique. 1994. "Las ansias de vivir y las normas del querer. Amores y 'mala vida' en Venezuela colonial”. En: Pino Iturrieta, Elías (coordinador). Quimeras de amor, honor y pecado en el siglo XVIII venezolano. Caracas: Planeta.

Levaggi, Abelardo. 1975. "Las penas de muerte y aflicción en el derecho indiano rioplatense". En: Revista de Historia del Derecho, 3: 89-90.

Lira Montt, Luis. 1979. "Estudiantes cuyanos, tucumanos, rioplatenses y paraguayos en la Real Universidad de San Felipe y Colegios de Santiago de Chile, 1612-1817, Historia $\mathrm{N}^{\circ} 14$ (Santiago de Chile).

Los códigos españoles concordados y anotados. Código de las Siete Partidas. 1872. Madrid: Antonio de San Martín Editor, $2^{\text {da }}$ edición.

Molina, Ricardo. 2004. "Desterrados, delitos y penas en la plaza y presidio de Valdivia en la segunda mitad del siglo XVIII". Ponencia presentada en "Jornadas de Historia Regional", Concepción, 19, 20 y 21 de octubre.

Morales Guiñazú, Fernando. 1936. Los corregidores y subdel egados deCuyo 15611810. Buenos Aires: Publicaciones del Instituto de Investigaciones Históricas de la Facultad de Filosofía y Letras.

. 1938. "Los conquistadores", Revista de la Junta de Estudios Históricos de M endoza, tomo XII (Mendoza).

Peña y Lillo, Silvestre. 1997. "Gregorio Puebla, tronco de una frondosa familia mendocina", Revista de la Junta de Estudios Históricos de M endoza, $3^{\text {era }}$ época, $\mathrm{N}^{\circ} 1$ (Mendoza).

Silva Riquer, Jorge. 2001. "La organización de las tiendas pulperas en la ciudad de México, siglo XVIII", en Manuel Miño Grijalva (editor) Censo depoblación de la ciudad de M éxico, 1790. Censo de Revillagigedo. México: El Colegio de México - Instituto Nacional de Estadística, Geografía e Informática.

Tomás y Valiente, Francisco. 1969. El derecho penal en la monarquía absoluta, siglos XVI - XVII - XVIII. Madrid: Tecnos.

Verdaguer, Aníbal. 1932. Historia eclesiástica deCuyo. Milano: Premiata Imprenta Salesiana. 